\title{
Electro-Thermomechanical Characterization of Ti-Ni Shape Memory Alloy Thin Wires
}

\author{
Maria Marony Sousa Farias Nascimento ${ }^{\mathrm{a}}$, Carlos José de Araújo ${ }^{\mathrm{b} *}$, \\ José Sérgio da Rocha Neto ${ }^{\text {a }}$ Antonio Marcus Nogueira de Lima ${ }^{\mathrm{a}}$ \\ ${ }^{a}$ Department of Electrical Engineering, Universidade Federal de Campina Grande, \\ Av. Aprígio Veloso, 882, Bodocongó, Campina Grande - PB, Brazil \\ ${ }^{\mathrm{b}}$ Department of Mechanical Engineering, Universidade Federal de Campina Grande, \\ Av. Aprígio Veloso, 882, Bodocongó, Campina Grande - PB, Brazil
}

Received: December 2, 2004; Revised: July 13, 2005

\begin{abstract}
The use of shape memory alloys (SMA) as smart structures and other modern applications require a previous evaluation of its performance under load as well as a training procedure. In general, these requirements lead to the design and assembly of a specific test bench. In this work, an experimental set-up was specially designed to perform the electro-thermomechanical characterization of SMA wires. This apparatus was used to determine the strain-temperature $(\varepsilon-T)$ and electrical resistance-temperature $(\mathrm{R}-\mathrm{T})$ hysteretic characteristics curves of a Ti-Ni shape memory wire ( $90 \mathrm{~mm}$ in length and $150 \mu \mathrm{m}$ in diameter) under mechanical load. The SMA wire is loaded by means of constant weights and a controlled system for injection of electrical power allows performing the heating-cooling cycles. The obtained hysteretic $\varepsilon-\mathrm{T}$ and $\mathrm{R}$ - $\mathrm{T}$ characteristics curves for some levels of applied loads are used to determine important shape memory parameters, like martensitic transformation temperatures, temperature hysteresis, temperature slopes and shape memory effect under load. These parameters were in accord with the ones found in literature for the studied SMA wires.
\end{abstract}

Keywords: shape memory alloys, Ti-Ni alloys, thermomechanical behavior, smart materials

\section{Introduction}

Shape memory alloys (SMA) are active metallic materials classified nowadays as "smart" or "intelligent" materials along with piezoelectric ceramic and polymers, eletroactive plastics, electro-rheological and magneto-rheological fluids and others. These materials are naturally considered as sensor-actuator elements demonstrating large possibilities for applications in high technology smart systems ${ }^{1}$. For any application, the selected SMA must be previously characterized concerning mainly its transformation temperatures and strain variation. Under stress free condition, this characterization is generally performed using differential scanning calorimetry (DSC) analysis and electrical resistivity (ER) measurements. In theses cases, only transformation temperatures and other physical parameters, like enthalpy and absolute electrical resistance, can be determined. For tests involving heating-cooling cycles under external load, commercial thermomecanical analyzers (TMA) ${ }^{2-4}$ and adaptation of the ER technique , $^{5,6}$ have been used to determine both transformation temperatures and strains. In all cases, heating of the sample is carried out by an electrical furnace, as in commercial DSC and TMA apparatus, or by circulation oil baths as in some ER test benches, and temperature is a parameter directly measured and controlled. However, the heating and cooling of SMA by direct passage of electrical current through the wire sample accompanied of electrical resistance and strain measurements, is a challenge that was not yet fully explored. In this case, when the SMA wire sample is very thin, direct measurement of SMA temperature becomes difficult. In this work, an experimental set-up was specially designed to perform electro-thermal cycles under constant load in thin SMA wires measuring simultaneously its absolute electrical resistance and strain. The apparatus was employed to determine the strain-temperature
$(\varepsilon-T)$ and electrical resistance-temperature $(\mathrm{R}-\mathrm{T})$ hysteresis loops of an equiatomic SMA Ti-Ni wire having $150 \mu \mathrm{m}$ in diameter being uniaxially loaded in the range of 140 to $225 \mathrm{MPa}$.

\section{Experimental Procedure}

\subsection{Description of the test apparatus}

Figure 1 illustrates the experimental test bench specially designed to perform eletro-thermomechanical characterization of thin SMA wires. This apparatus is composed basically of a simple mechanical structure, a LVDT (Linear Variable Displacement Transducer) displacement sensor and a controlled system for electrical heating - cooling cycles and data acquisition. In the mechanical structure, the frame in aluminum (6) was manufactured using corner shelf's $(50 \times 50 \mathrm{~mm})$ joined by screws. On this frame are assembled the fixed guide axis (7), the mobile one (4) and the LVDT sensor (1). The SMA wire sample (8) is fastened by nylon grips $(2,3)$ while loading is carried out by means of weights deposited on a platform (8) to assure an uniaxial tensile state on the SMA wire. The strain variation due to loading and/or thermal cycling of the SMA can be monitored by the model AX/5.0/P LVDT displacement sensor (supplied by Solartron Inc) with accuracy of the order of $5 \mu \mathrm{m}$ and its sensibility was experimentally confirmed as being of $0.5 \mathrm{~mm} / \mathrm{V}$. The control system consists of a DC programmable HP E3631A power supply and three HP 34401 multimeters, all equipped with GPIB (IEEE-488) interface for data acquisition. A voltage/current converter allows to create a desired current waveform $\mathrm{i}(\mathrm{t})$ for controlled heating and cooling of the SMA 


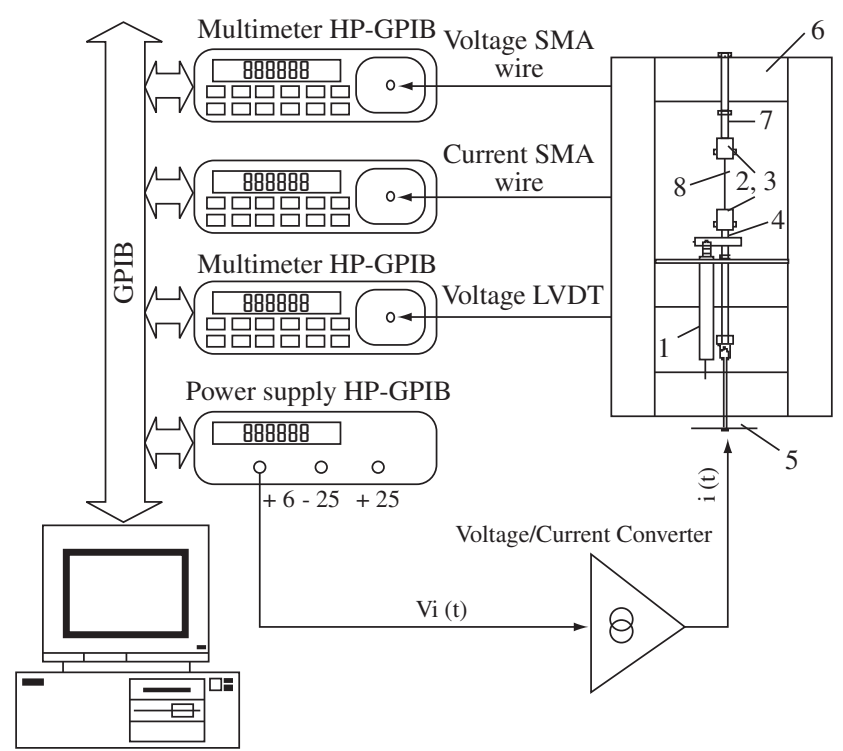

Figure 1. Mechanical structure of the testing bench and data acquisition system: 1) LVDT displacement sensor; 2, 3) mechanical grips; 4) guiding LVDT; 5) load (weight); 6) frame; 7) guiding rod; and 8) SMA wire.

wire. The multimeters illustrated in Figure 1 measure voltage and electrical current through the SMA wire and LVDT voltage signal. Data acquisition is carried out using an IBM PC 486DX4 - S100 computer having a GPIB card.

The voltage/current converter illustrated in Figure 1 is composed of an operational amplifier (TL084), a transistor (BD136), a resistor $\left(R_{i}=8.9 \Omega\right)$ and a reference resistor $\left(R_{R E F}=1 \mathrm{k} \Omega\right)$, as schematized in Figure 2. This voltage/current converter transform an input voltage $V_{i}(t)$ in electrical current $i(t)$ passing through the SMA wire for electrical heating. For a positive input voltage $V_{i}(t)$, the output voltage $V_{0}(t)$ in the operational amplifier is negative so that the transistor $\mathrm{T}_{1}$ allow the passage of electrical current through the SMA.

Figure 3 shows a picture of the experimental test bench described in Figure 1.

\subsection{Studied SMA wire}

The equiatomic Ti-Ni SMA wire with $150 \mu \mathrm{m}$ in diameter, used in this study, was supplied by Mondo-Tronics Inc. ${ }^{7}$. The samples have $90 \mathrm{~mm}$ in length and martensitic transformation temperatures, according to supplier, are $\mathrm{M}_{\mathrm{f}}=42{ }^{\circ} \mathrm{C}, \mathrm{M}_{\mathrm{s}}=52{ }^{\circ} \mathrm{C}, \mathrm{A}_{\mathrm{s}}=68^{\circ} \mathrm{C}$ and $\mathrm{A}_{\mathrm{f}}=78^{\circ} \mathrm{C}$.

\subsection{The electrical current - temperature model}

The experimental set-up illustrated in Figure 1 allows to measure at the same time the strain $(\varepsilon)$ and electrical resistance $(R)$ of the SMA wire as a function of electrical current $i(t)$. However, the characterization of these materials is undertaken regarding transformation temperatures, and not electrical current. Some authors ${ }^{8}$, even using electrical heating by Joule effect, have mentioned the installation of a thermocouple on the surface of the SMA wire aiming a direct measurement of the temperature change during passage of electrical current. However, considering the extremely reduced diameter of the SMA wire used in this study, installation of thermocouples directly on its surface was not possible. The use of

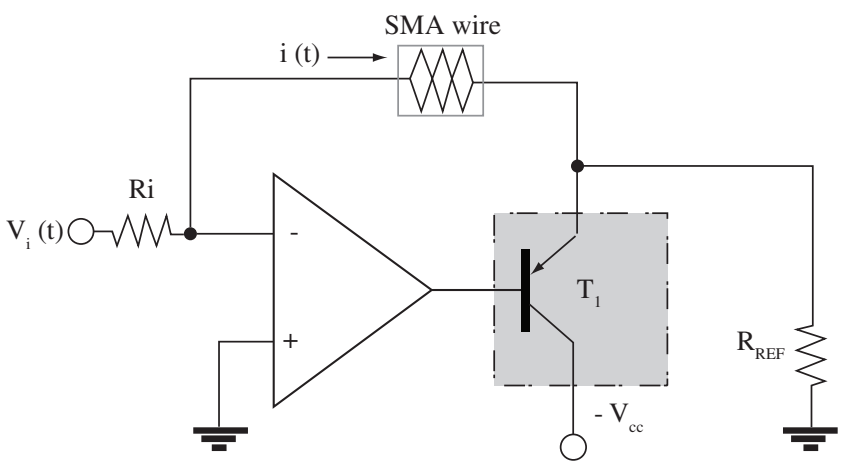

Figure 2. Electrical scheme of the voltage/current convert used to heat the SMA wire.

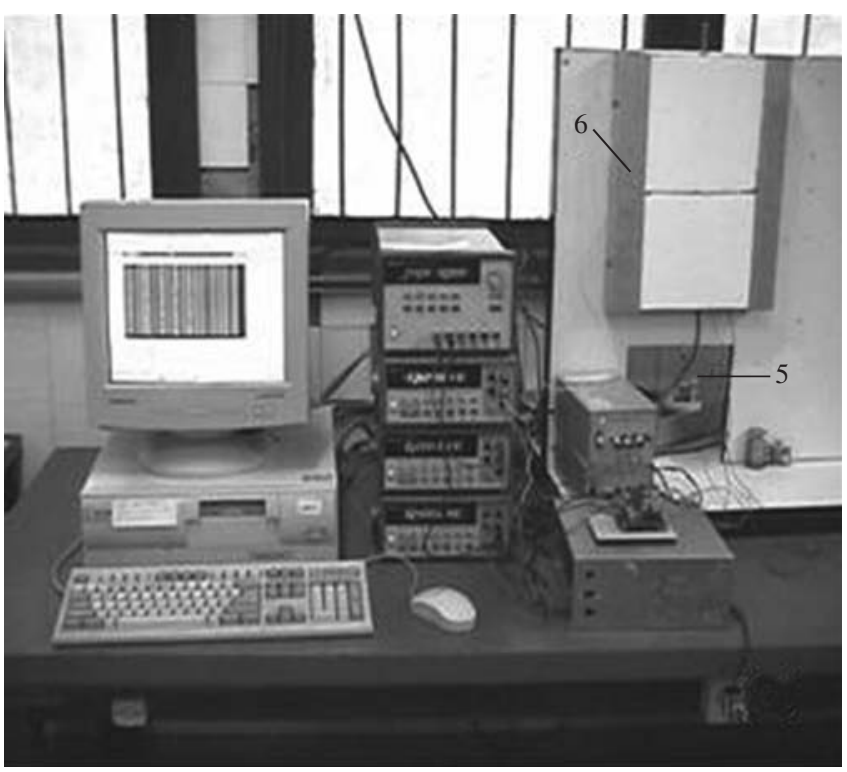

(a)

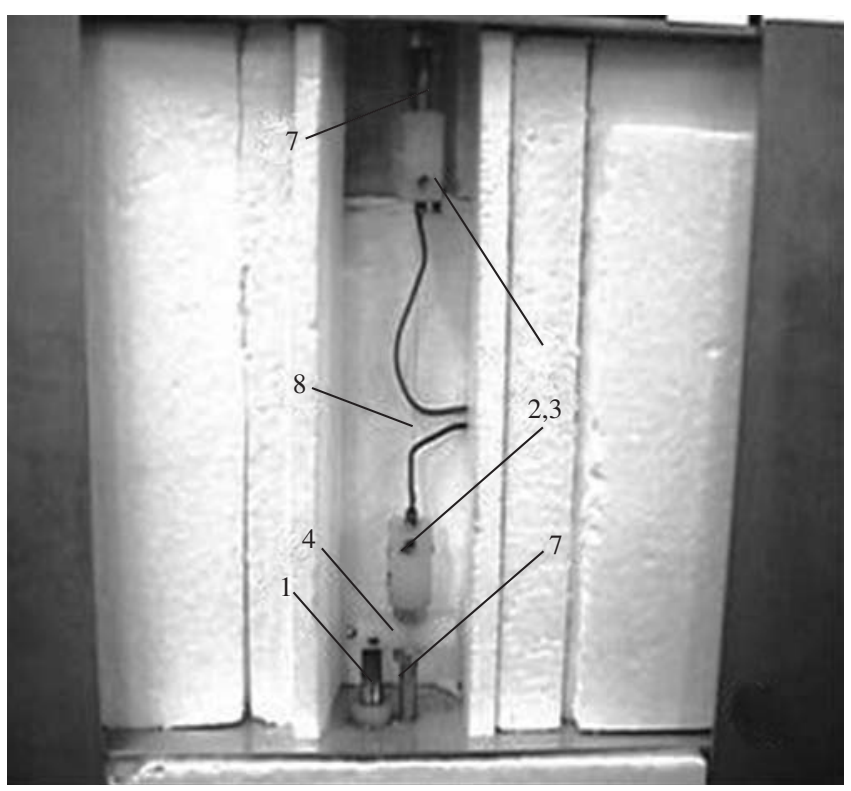

(b)

Figure 3. Picture of the test apparatus, a) Entire view; and b) Zoom view of the SMA wire. 
an infrared sensor based on pyroelectric detector was also rejected by the same reasons.

In the absence of an accurate and reliable technique for direct measurement of the SMA wire temperature it was estimated from the heat-transfer thermal equilibrium equation given by

$$
\rho \mathrm{C}_{\mathrm{p}} \mathrm{V} \frac{\mathrm{dT}}{\mathrm{dt}}=\mathrm{Ri}^{2}-\mathrm{hA}\left[\mathrm{T}-\mathrm{T}_{\infty}\right]
$$

where V, A and R are the volume, the surface area and the electrical resistance of the SMA wire, respectively. The specific mass $\rho$ and the specific heat $\mathrm{C}_{\mathrm{p}}$ are intrinsic properties of the material and $\mathrm{h}$ is the convective heat transfer coefficient between the wire and its surroundings at temperature $\mathrm{T}_{\infty}$.

Although frequently assumed, some physical parameters in Equation 1 are not constant during temperature variations, mostly in the transformation region. The volume change during transformation is negligible (of the order of $0.16 \%$ ), however meaningful changes can be verified in $C_{p}$ and $R$.

In this study, the parameters $R$ and $\varepsilon$ are measured for the heated SMA wire in steady-state condition. From Equation 1, the steady-state value of the wire temperature, for a step current $\mathrm{i}$ when $\mathrm{dT} / \mathrm{dt}=0$ is

$$
\mathrm{T}-\mathrm{T}_{\infty}=\frac{\mathrm{R}}{\mathrm{h} \cdot \mathrm{A}} \cdot \mathrm{i}^{2}
$$

Application of Equation 2 involves necessarily the estimation of the convective heat transfer coefficient between the wire and its surroundings (h). This estimation process was done by means of two experiments. The first one was carried out using an electrical furnace where the SMA wire was thermal cycled between $25^{\circ} \mathrm{C}$ and $90{ }^{\circ} \mathrm{C}$ for measurement of its electrical resistance as a function of temperature $(\mathrm{R}-\mathrm{T})$. The second experiment was performed using the experimental set-up described in Figure 1 with no external loads on the SMA wire. During these tests, the electrical resistance $v s$. current (R - i) was determined.

Then, using Equation 1 and considering that current and electrical resistance for the second experiment were measured in the steadystate condition, it is possible to use Equation 2 and the following identification problem can be established

$$
\mathrm{R}_{\mathrm{n}} \mathrm{i}_{\mathrm{n}}^{2}=\mathrm{hA}\left(\mathrm{T}_{\mathrm{n}}-\mathrm{T}_{\infty}\right) ; \mathrm{n}=1, \ldots, \mathrm{N}
$$

where $\mathrm{N}$ is the number of points. With the $\mathrm{R}_{\mathrm{n}}, \mathrm{i}_{\mathrm{n}}$ and $\mathrm{T}_{\mathrm{n}}$ obtained from the two described experiments, an identification problem to determine the convective heat transfer coefficient between the wire and its surroundings (h) can be calculated. Using the identification method proposed by Ljung ${ }^{9}$, which involves a group of candidate models and a general rule to evaluate the models from the data, identification of $h$ and $T_{\infty}$ becomes easy and the problem is solved according to equation:

$$
\mathrm{y}(\mathrm{x})=\alpha \mathrm{T}(\mathrm{x})-\beta
$$

where $\alpha=\mathrm{hA}, \beta=\mathrm{hAT}_{\infty}$ and $\mathrm{y}(\mathrm{x})=\mathrm{R}_{\mathrm{n}} \mathrm{i}_{\mathrm{n}}^{2}$.

By applying the least squares method for the Equation 4, the following values were identified: $\mathrm{h}=88.2 \mathrm{~W} / \mathrm{m}^{2} .{ }^{\circ} \mathrm{C}$ and $\mathrm{T}_{\infty}=25.1^{\circ} \mathrm{C}$. With these values, electrical current can be directly converted to temperature of the SMA wire using Equation 2.

\section{Results and Discussions}

\subsection{Thermal cycling of the SMA wire}

Figures 4 and 5 show, respectively, the electrical current waveform used to perform the heating-cooling cycles of SMA wire samples and the corresponding estimated temperatures from Equation 2. The heating - cooling current rate was $4.78 \mathrm{~mA} / \mathrm{min}$. Absolute temperatures can be obtained adding the $\mathrm{T}_{\infty}$ value to data from Figure 5 .

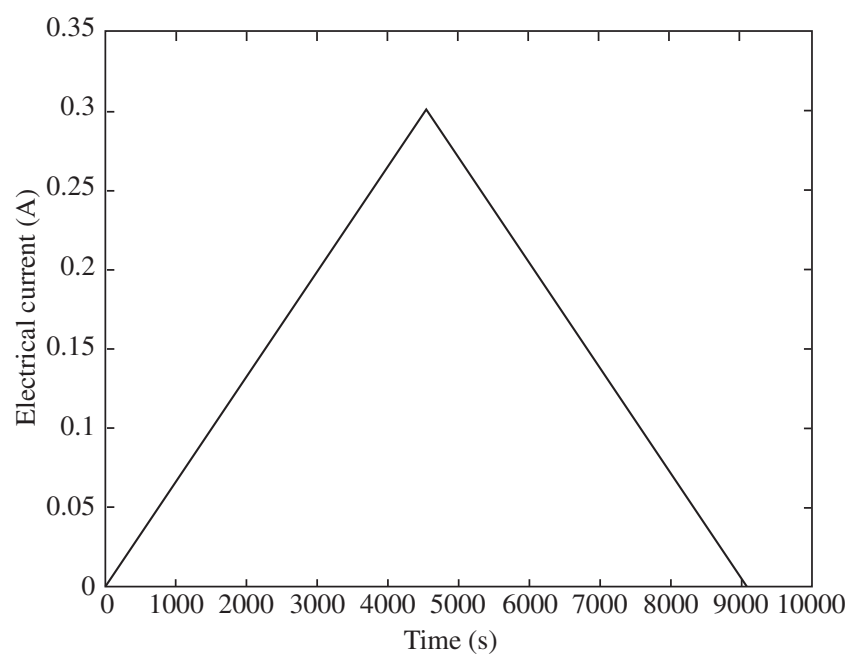

Figure 4. Electrical current waveform used to perform thermal cycles in the SMA wire samples.

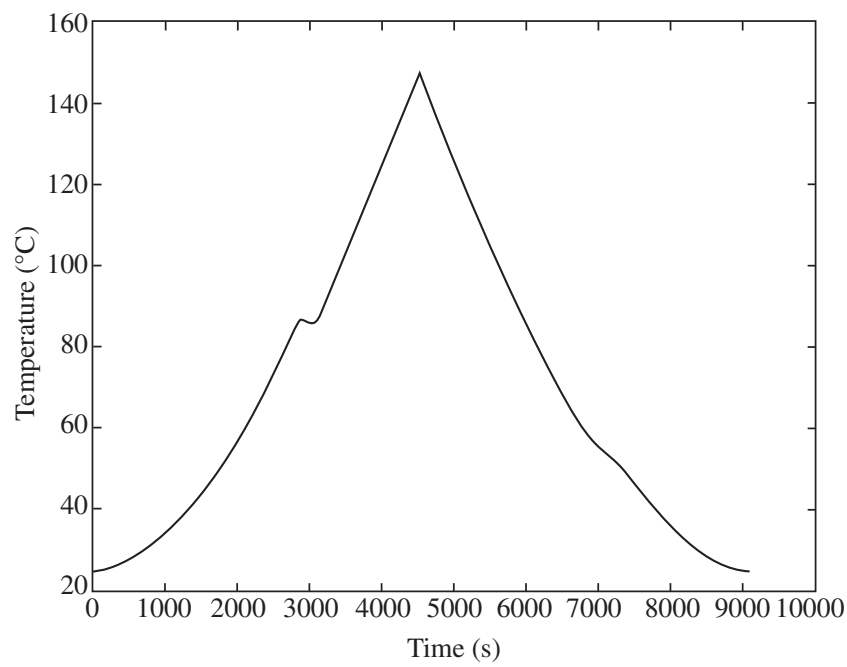

Figure 5. Temperature waveform estimated using Equation 2.

\subsection{Electro-thermomechanical characterization of the SMA wire}

\subsubsection{Characterization of the $\varepsilon-\mathrm{T}$ hysteresis}

Figure 6 shows the strain $v s$. temperature hysteresis loops for applied loads in the range of $142 \mathrm{MPa}(255 \mathrm{~g}$ ) to $225 \mathrm{MPa}$ (405 g). For all applied loads, contraction of the SMA wire was practically constant between $4,5 \%$ and $5 \%$, indicating that between 142 and $225 \mathrm{MPa}$ a complete orientation of martensite variants occurs. Besides, it is clearly observed from Figure 6 a displacement of $\varepsilon-T$ hysteresis loops towards the higher temperatures with increasing the applied load. This behavior is typical of the SMA's and corresponds to an increase of transformation temperatures as a function of the mechanical loading, being described by a modified Clausius-Clayperon type law ${ }^{10}$. The $\varepsilon$ - T hysteresis loops shown in Figure 6 were recently simulated by Nascimento ${ }^{11}$ using a new model adapted from the limiting loop proximity hysteresis model developed by Almeida et $\mathrm{al}^{12}$. 
The martensitic transformation temperatures plotted in Figure 7 were directly measured from Figure 6 using the tangent method $^{13}$. The $\mathrm{C}_{\mathrm{A}}$ and $\mathrm{C}_{\mathrm{M}}$ slopes define the linear relationship respectively between the austenitic $\left(\mathrm{A}_{\mathrm{s}}\right.$ and $\left.\mathrm{A}_{\mathrm{f}}\right)$ and martensitic $\left(\mathrm{M}_{\mathrm{s}}\right.$ and $\left.\mathrm{M}_{\mathrm{f}}\right)$ transformation temperatures and applied stress. These slopes were $\mathrm{C}_{\mathrm{A}}=6.8$ and $\mathrm{C}_{\mathrm{M}}=4.3 \mathrm{MPa} /{ }^{\circ} \mathrm{C}$, and they are in accord with the large range presented in the literature (between 3 and $20 \mathrm{MPa} /{ }^{\circ} \mathrm{C}$ ) ${ }^{10}$.

Figure 6 also indicates a reduction of the hysteresis width as a function of the applied stress, as confirmed in Figure 8. This hysteresis width drops of about $10 \mathrm{C}$ in the range of $80 \mathrm{MPa}$ to $225 \mathrm{MPa}$. These results are compatible with the ones presented by De Araujo et al. ${ }^{13}$ for a Ti-Ni-Cu SMA wire.

\subsubsection{Characterization of the $\mathrm{R}$ - $\mathrm{T}$ hysteresis}

For each current value composing the waveform shown in Figure 4, it was measured, beyond the contraction of the SMA wire, its absolute electrical resistance. Thus, the hysteretic resistance $v s$. temperature behavior was determined as shown in Figure 9 for the same stress range of Figure 6.

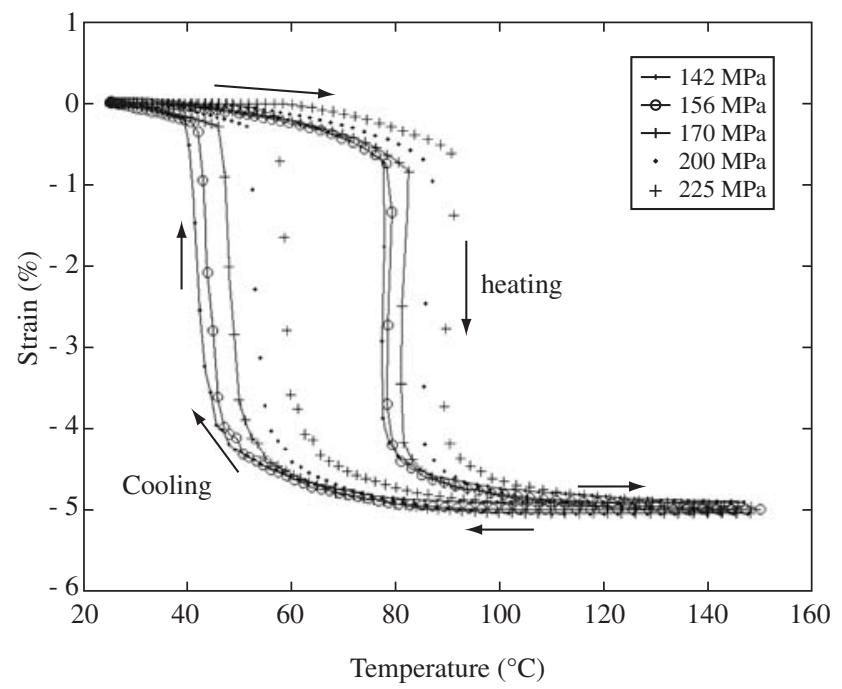

Figure 6. $\varepsilon$ - T hysteresis loops for some applied loads on the SMA wire.

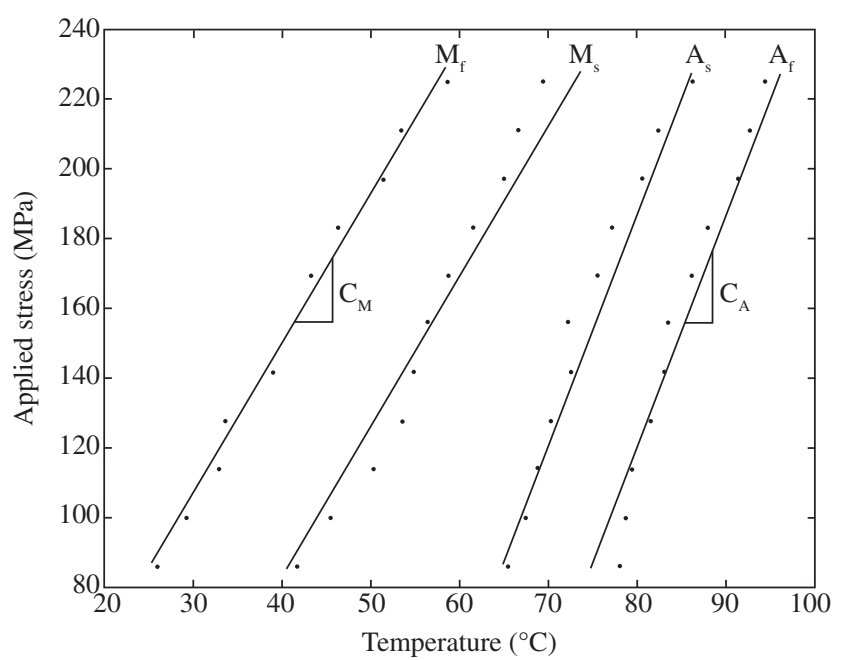

Figure 7. Transformation temperatures as a function of applied load on the SMA wire.
From Figure 9, it is observed that, for all stresses in the studied range, the electrical resistance reaches maximum values between 2 to $3 \%$ higher than the ones measured at $25{ }^{\circ} \mathrm{C}$. In addition, for all applied loads, the electrical resistance decreases of about 17 to $18 \%$ in the transformation region comparing with maximum resistance.

By combining results of Figures 6 and 9, the $\varepsilon$ - R behavior can be obtained as shown in Figure 10 for an applied load corresponding to $200 \mathrm{MPa}$. Figure 10 confirm that it is not possible to obtain a linear relationship without hysteresis between $\varepsilon$ and $R$ for the studied SMA wire, contrarily to the results verified by De Araújo et al. ${ }^{13}$ for Ti-Ni-Cu SMA wires.

This absence of linearity without hysteresis in the $\varepsilon-\mathrm{R}$ characteristic curve occurs because the $\varepsilon-\mathrm{T}$ and $\mathrm{R}$ - T loops do not have exactly the same form, as can be verified comparing Figures 6 and 9. Considering the R - T characteristic curve in Figure 9 during cooling, it can be observed that transformation occurs slowly between 5 and $5.5 \Omega$, while transformation in the $\varepsilon-\mathrm{T}$ behavior develop rapidly in a narrow temperature range. This irregularity in the $\mathrm{R}-\mathrm{T}$ loops can indicate the presence of an intermediary austenite to R-phase

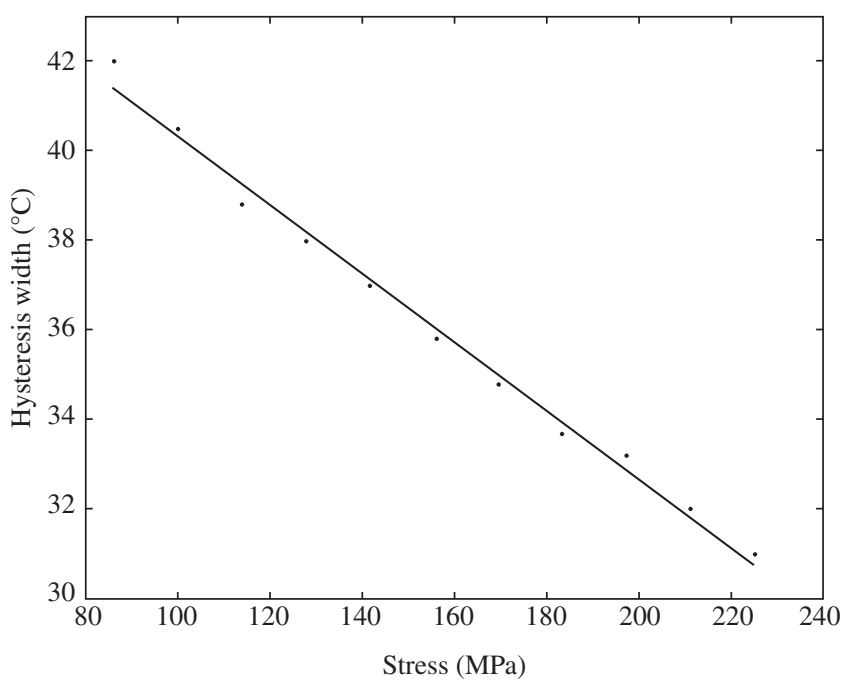

Figure 8. Hysteresis width as a function of applied load on the SMA wire.

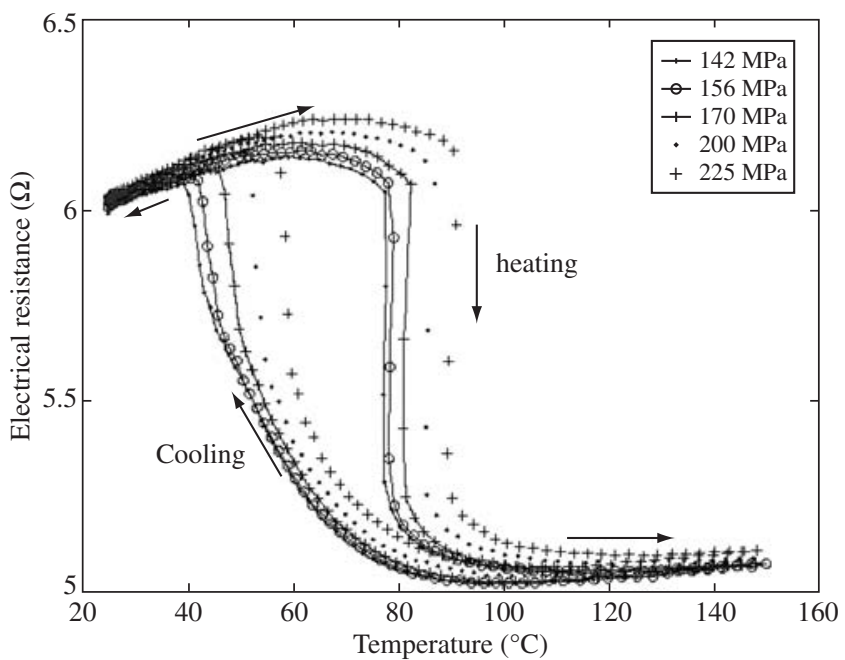

Figure 9. R - T hysteresis loops for some applied loads on the SMA wire. 


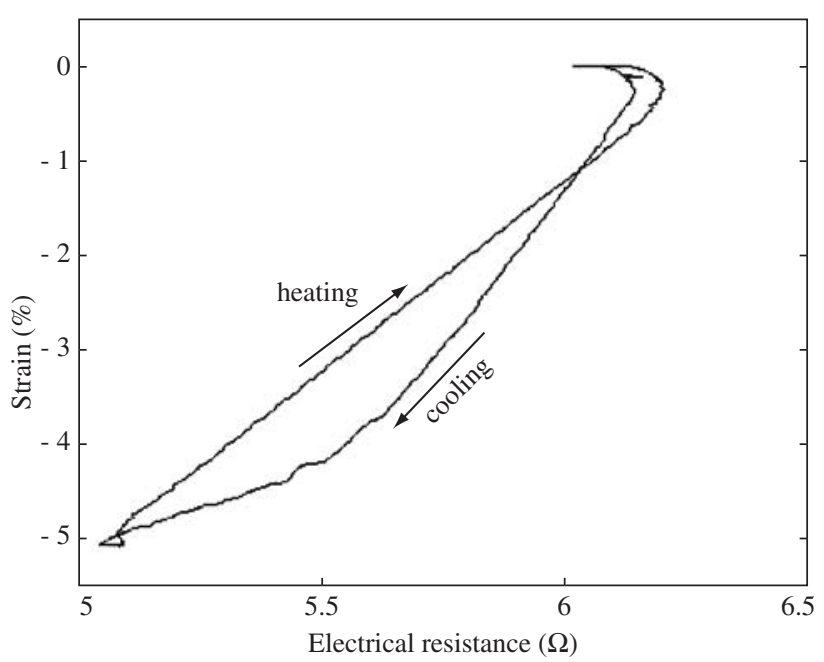

Figure 10. $\varepsilon$ - R behavior for SMA wire loaded under $200 \mathrm{MPa}$.

transformation, susceptible to appear in the Ti-Ni binary SMA and responsible by the absence of linearity in the $\varepsilon-\mathrm{R}$ behavior ${ }^{6}$.

\section{Conclusions}

In this work the electro-thermomechanical characterization of a Ti-Ni SMA wire with $150 \mu \mathrm{m}$ in diameter was carried out using an experimental test bench specially designed to perform direct electrical heating and cooling of the sample by Joule effect. This apparatus has allowed simultaneous measurements of displacement and electrical resistance as a function of the estimated temperature of samples loaded by constant weights.

For uniaxial applied tensile stresses between 142 and $225 \mathrm{MPa}$, contraction and elongation by shape memory effect under load was practically constant, of the order of $5 \%$ in relation to its initial length.

By raising applied stress, a linear increase of austenitic and martensitic transformation temperatures were also verified with slopes of 6.8 and $4.3 \mathrm{MPa} /{ }^{\circ} \mathrm{C}$, respectively. In opposition, thermal hysteresis drops about $10{ }^{\circ} \mathrm{C}$ for the same applied stress range.

Combining $\varepsilon-\mathrm{T}$ and $\mathrm{R}-\mathrm{T}$ loops lead to obtaining the $\varepsilon-\mathrm{R}$ characteristic of the SMA wire. However, due to an anomaly in the $\mathrm{R}$ - T loop during cooling, this $\varepsilon$ - $\mathrm{R}$ behavior was not linear without hysteresis, as it can be eventually expected.

\section{Acknowledgments}

Research supported by the Brazilian agencies: Conselho Nacional de Desenvolvimento Científico e Tecnológico (CNPq), Fundo Setorial de Energia (CT-Energ, CNPq grant number: 400724/2003-0) and Coordenação de Aperfeiçoamento de Pessoal de Nível Superior (CAPES).

\section{References}

1. Srinivasan AV, McFarland DM. Smart Structures: Analysis and Design. Cambridge, UK: Cambridge University Press; 2001.

2. Zheng Y, Schrooten J, Cui L, Van Humbeeck J. Constrained thermoelastic martensitic transformation studied by modulated DSC. Acta Materialia. 2003; 51(18):5467-5475.

3. Xu Y, Otsuka K, Toyama N, Yoshida H, Nagai H, Kishi T. Additive nature of recovery strains in heavily cold-worked shape memory alloys. Scripta Materialia. 2003; 48(6):803-808.

4. Liu Y. Mechanical and thermomechanical properties of a $\mathrm{Ti}_{50} \mathrm{Ni}_{25} \mathrm{Cu}_{25}$ melt spun ribbon. Materials Science and Engineering A. 2003; A354:286291.

5. De Araújo CJ. Comportement cyclique de fils en alliage à mémoire de forme Ti-Ni-Cu: analyse electro-thermomécanique, dégradation et fatigue par cyclage thermique sous contrainte. [Thèse de Doctorat]. Villeurbanne: INSA-Lyon; 1999.

6. De Araújo CJ, Lopez-Cuellar E, Morin M, Guénin G. Sobre a possibilidade de controlar atuadores à memória de forma via medidas de variação de resistência elétrica: uma análise experimental. Anais do $V$ Congreso Iberoamericano de Ingenieria Mecânica (CIDIM); 2001 Mérida, Venezuela. 2001. p. 345-350.

7. Gilbertson RB. Muscle Wires Projet Book. San Rafael, CA (USA): Mondo-Tronics Inc.; 2000.

8. Brailovski V, Trochu F, Daigneault G. Temporal characteristics of shape memory linear actuators and their application to circuit breakers. Materials \& Design. 1996; 17(3):151-158.

9. Ljung L. System Identification: Theory for the User. Linkoping University, Sweden: Prentice Hall; 1999.

10. Otsuka K, Wayman CM. Shape Memory Materials. Cambridge, UK: Cambridge University Press; 1998.

11. Nascimento MMSF. Contribuição ao estudo da histerese em ligas com memória de forma. [Dissertação de Mestrado]. Campina Grande, PB: Universidade Federal de Campina Grande; 2003.

12. Almeida LAL, Deep GS, Lima AMN, Neff H. The limiting loop proximity $\left(\mathrm{L}^{2} \mathrm{P}\right)$ hysteresis model. IEEE Transaction on Magnetics. 2002; 39(1):523-528.

13. De Araújo CJ, Gonzalez CH, Morin M, Guénin G. Influence of the mechanical loading history on the stress assisted two way memory effect in a Ti-Ni-Cu alloy. Materials Research. 2001; 4(3):181-188. 